\title{
Incorporating active-learning techniques into the photonics-related teaching in the Erasmus Mundus Master in "Color in Informatics and Media Technology"
}

Antonio Pozo, Manuel Rubiño, Javier Hernández-Andrés, Juan Nieves

Antonio M. Pozo, Manuel Rubiño, Javier Hernández-Andrés, Juan Luis Nieves, "Incorporating active-learning techniques into the photonics-related teaching in the Erasmus Mundus Master in "Color in Informatics and Media Technology"," Proc. SPIE 9289, 12th Education and Training in Optics and Photonics Conference, 92892Q (17 July 2014); doi: 10.1117/12.2070761

Event: 12th Education and Training in Optics and Photonics Conference, 2013, Porto, Portugal 


\title{
Incorporating active-learning techniques into the photonics-related teaching in the Erasmus Mundus Master in "Color in Informatics and Media Technology"
}

\author{
Antonio M. Pozo*, Manuel Rubiño, Javier Hernández-Andrés, Juan Luis Nieves \\ Departamento de Óptica, Facultad de Ciencias, Universidad de Granada, Granada 18071, Spain
}

\begin{abstract}
In this work, we present a teaching methodology using active-learning techniques in the course "Devices and Instrumentation" of the Erasmus Mundus Master's Degree in "Color in Informatics and Media Technology" (CIMET). A part of the course "Devices and Instrumentation" of this Master's is dedicated to the study of image sensors and methods to evaluate their image quality. The teaching methodology that we present consists of incorporating practical activities during the traditional lectures. One of the innovative aspects of this teaching methodology is that students apply the concepts and methods studied in class to real devices. For this, students use their own digital cameras, webcams, or cellphone cameras in class. These activities provide students a better understanding of the theoretical subject given in class and encourage the active participation of students.
\end{abstract}

Keywords: Teaching methodology, active-learning methodology, electro-optical devices and instrumentation, ImageJ software.

\section{INTRODUCTION}

The CIMET Consortium is composed of four European Universities renowned within the color-research community: University Jean Monnet (France), University of Eastern Finland, Gjøvik University College (Norway) and University of Granada (Spain). Since 2008, the CIMET Consortium has offered a two-year Master's Course "Color in Informatics and Media Technology". CIMET Master's programme is broadly interdisciplinary and the course curriculum covers innovative areas such as color, photonics, computer vision and imaging science, computer science, and multimedia technology. The programme objective is to educate students in advanced methodologies and models in computational color science.

CIMET offers three areas of specialization: Color-Imaging Science, Spectral Color Science, and Multimedia Technology Science. These fields, being emerging areas, are rapidly evolving, exert growing impact on the Information Society Technologies, and thus require specialists and specialized skills. The specificities of the CIMET Master's also include innovative pedagogical methods of teaching and learning and the Cross-European mobility scheme offered to students and teaching staff. Those two aspects are indeed enhancing the excellence and added value of the Master's programme.

The CIMET curriculum is intended for top-level graduates in physics, optics, imaging science, computer science, mathematics or any discipline pertaining to the quantitative description of color. Courses are structured according to the ECTS with 120 credits acquired over four semesters of full-time study.

The CIMET master's teaching consists of traditional lectures, in which the instructors present relevant theoretical knowledge and impart practical knowledge through laboratory sessions. However, teaching based on traditional lectures can sometimes lead to a passive attitude on the part of students. Therefore, it is necessary to incorporate innovative methods to make the course engaging for students while encouraging their participation in the learning process. One way to motivate student involvement in the teaching-learning process is by incorporating active methodologies. ${ }^{1,2}$

*ampmolin@ugr.es; phone (34) 958241902; fax (34) 958248533

12th Education and Training in Optics and Photonics Conference, edited by

Manuel F. P. C. Martins Costa, Mourad Zghal, Proc. of SPIE Vol. 9289, 92892Q

(C) 2014 SPIE, OSA, IEEE, ICO · doi: 10.1117/12.2070761 
In this work, we present a teaching methodology which has been incorporated into the course "Devices and Instrumentation" of the Erasmus Mundus CIMET Master's Degree. Our aim is to improve the teaching of theory classes. We seek not only to stimulate active student participation in the classroom and the group work, ${ }^{3,4}$ but also to aid students in acquiring a better comprehension of the concepts and methods explained in the theory classes. For this, we have designed practical activities that the students will carry out during the theory classes, using free software for image processing.

Finally, we should add that these activities differ from those performed by students in laboratory sessions. Therefore, they do not replace laboratory classes but rather complement them, as not all the material studied in the theory classes can be put into practice in the laboratory sessions. In addition, the philosophy of the laboratory sessions is different, as in these activities the students apply advanced methods using specific instruments, requiring therefore greater execution time.

\section{OBJECTIVES}

The specific objectives that we pursue through this methodology are:

- To improve the teaching in the theory classes of the course entitled "Devices and Instrumentation" of the CIMET Master's Degree, by the incorporation of active methodologies in the theory classes.

- To stimulate the active participation of the students during the theory classes.

- To foment the study and in-depth understanding of the material.

- To complement the practical training in the laboratory.

- To foment and disseminate within the university community the use of free software by students as well as professors.

- To motivate work in groups.

\section{TEACHING METHODOLOGY}

As commented in Section 1, our teaching methodology is currently being conducted in the course "Devices and Instrumentation" of the CIMET Master's Degree. A large part of this course is dedicated to studying electro-optical imaging systems, ${ }^{5,6}$ such as CCD cameras. The theory classes present, among other aspects, Fourier transform, fundamental concepts such as spatial frequency, or the Modulation Transfer Function (MTF) to evaluate the image quality of digital cameras. The teaching methodology consists of incorporating active-learning techniques into the traditional lectures. For this, the students undertake practical activities during traditional lectures.

After the professor has imparted a certain amount of theory, the students will be informed about the activities to be performed in the next class session. The students will have a manual prepared by the professors of the course, in which the activities will be described. Also, the students will receive a collection of images necessary to carry out the activities.

For the analysis and processing of the images, the students will use the free software ImageJ. ${ }^{7}$ Unlike most imageprocessing programs, ImageJ does not have a main work area. ImageJ's main window actually contains only a menu bar including all the menu commands, a toolbar, a status bar and a progress bar (Figure 1). Images, histograms, profiles, etc. are displayed in additional windows.

The professors of the course chose the ImageJ software because of its characteristics. It can display, edit, analyse, process, save and print 8-bit, 16-bit, and 32-bit images. It is a public-domain open-source software based on JAVA, which is currently also used in the sphere of scientific research for processing and analysing digital images. As opposed to other software, such as MATLAB, ImageJ requires no knowledge of programming and permits image characteristics to be shown with its histogram, intensity surface, intensity profiles, and Fourier transform, in addition to allowing the application of different digital filters. In addition, this software is tremendously fast, making it ideal for use during the theory sessions, in such a way that it can be combined with theory and practice in a seamless manner. Although its use requires no knowledge of programming, programs can be created using plugins and macros. 


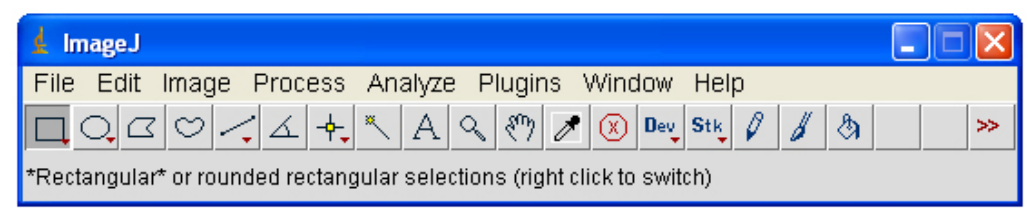

Figure 1. Main window of the ImageJ software (version 1.47k).

For the execution of the activities, the students take their laptop computers to class together with some system to capture images, such as their own digital cameras, webcams, or cell phones.

The activities take place in four sessions of one hour each. These sessions include an introduction to ImageJ, 2D Fourier transform of images, calibration of raw images, and contrast-transfer-function measurement of digital cameras. In the first session, the students install ImageJ in their laptops and then familiarize themselves with the use of the menu bar and tool bar of the software, performing activities chosen from the manual by the professor. In addition, in this session, the students learn to interpret the histogram of an image, to deal with intensity profiles (Figure 2) and intensity surfaces (Figure 3), as well to eliminate noise from images using the digital-filter application.

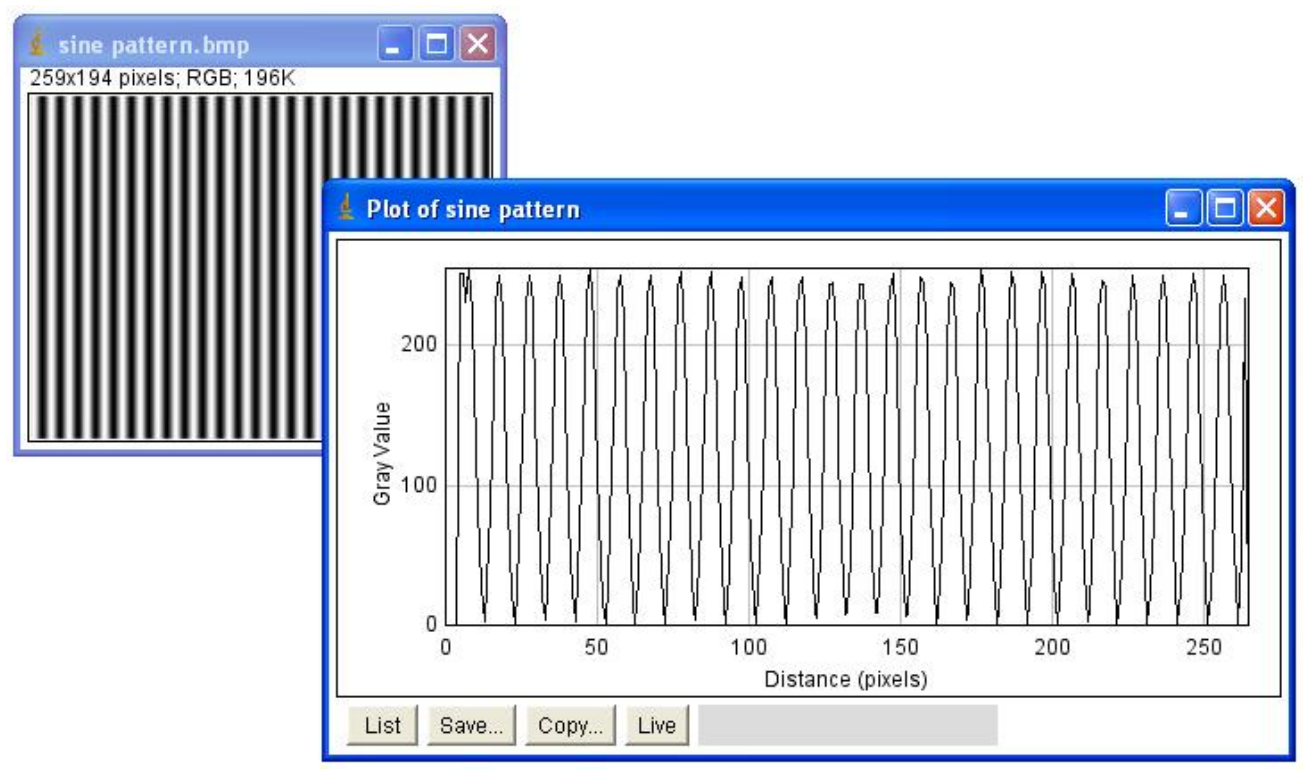

Figure 2. Sine pattern and its intensity profile get by ImageJ. 


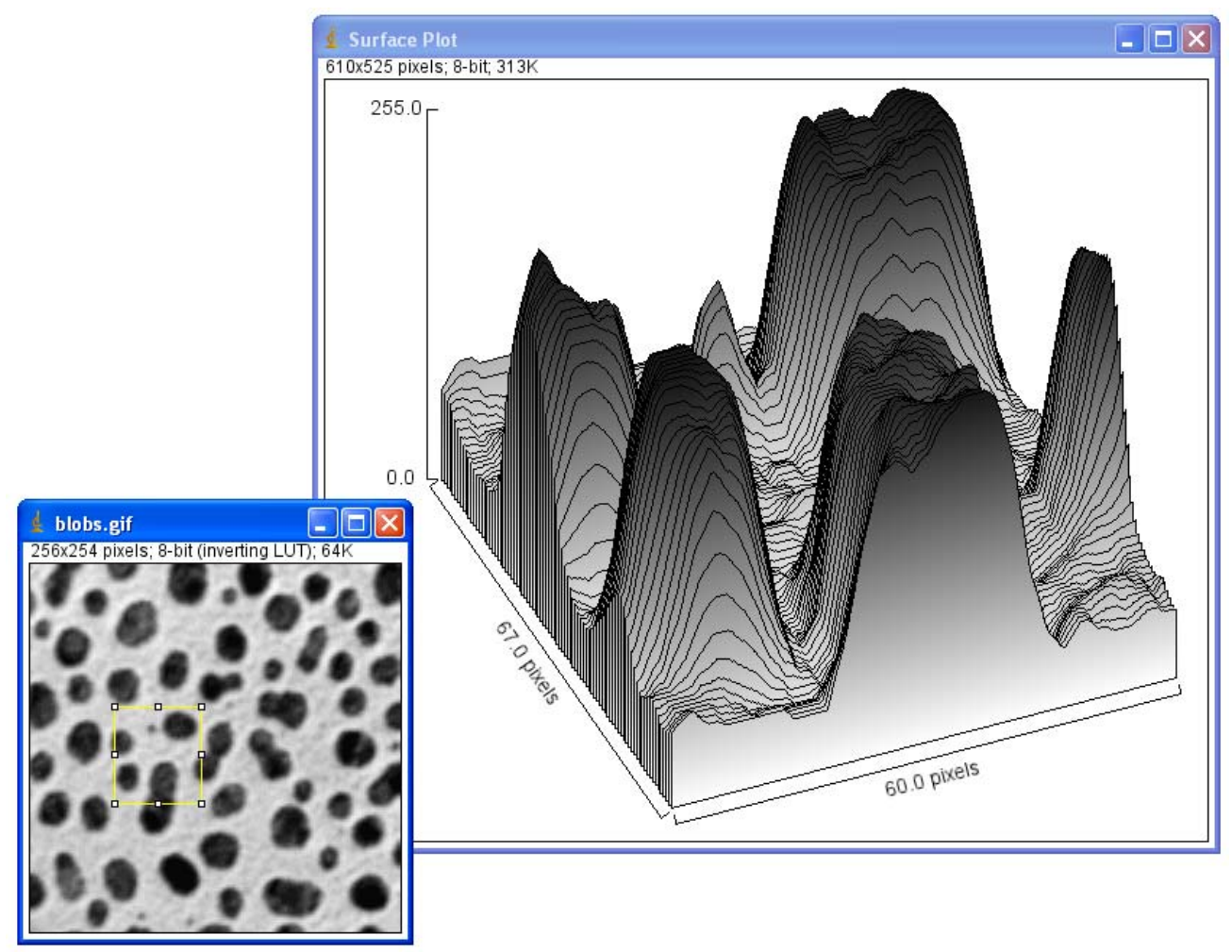

Figure 3. Surface plot corresponding to the yellow region on the image of blobs. The image of blobs is an example provided by ImageJ.

In the second session, the students learn to how to visualize and interpret the 2D Fourier Transform by ImageJ. Also, in this session they learn to filter images in the spatial-frequency domain. Figure 4 shows one of the examples that the students analyse, which consists of a wood texture and its Fourier transform by ImageJ. Finally, the students take photographs with their cameras of different objects or patterns that they find in the classroom itself and afterwards they conduct the Fourier transform of these images and discuss the results with their classmates.

In the third session, the students apply the calibration algorithm for raw images studied in class, which consists of calibrating the raw images taking into account the dark and flat images. First, the students practice with the collection of images provided by the professor. Afterwards, the students apply the calibration algorithm for images that they captured in class with their own digital cameras, webcams, or cell-phone cameras.

Finally, in the fourth session, the students evaluate the image quality from their own digital cameras by the MTF. For this, they capture the image of a bar pattern such as the USAF 1951 target, or a pattern shown on the screen of their laptops or the professor's laptop. After finishing the capture of images and the determination of the MTF, the students compare the results found with their devices with respect to the results found by the other classmates. This encourages work in groups and critical analysis of the results. 


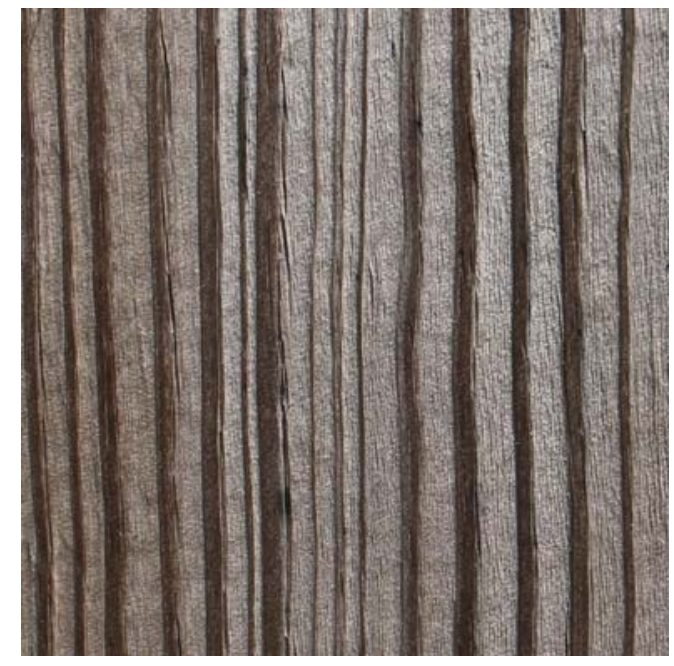

(a)

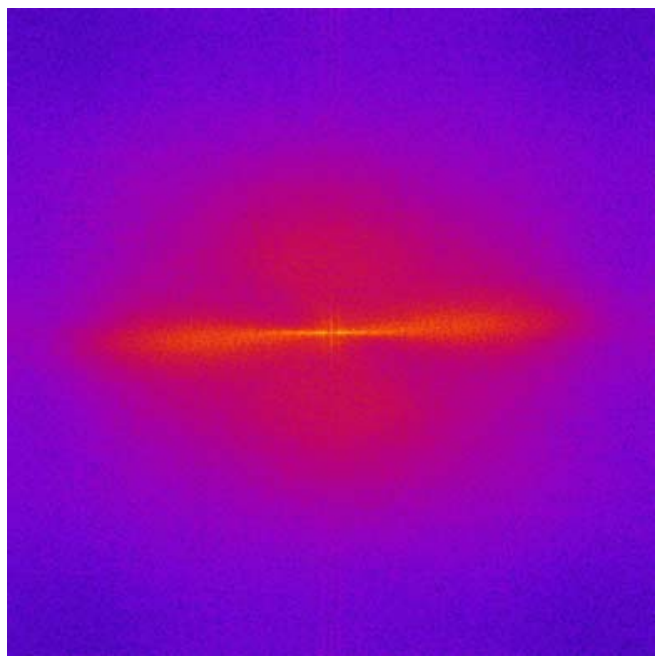

(b)

Figure 4. (a) Wood texture and (b) its Fourier transform. The wood-texture image was downloaded from http://www.stockvault.net.

As explained above, one of the innovative aspects of this methodology is that the students use real devices in several of the activities proposed. These devices, whether the digital cameras, webcams, or cell-phone cameras belong to the students themselves. In this way, the activities become attractive to the student, as the concepts and methods studied in theory class are applied to the students' own devices, thereby facilitating better comprehension of the theoretic material studied.

Finally, we should mention that the use of real devices does not constitute a restriction for applying this teaching methodology to other similar subjects. In fact, it would suffice for the professor to provide the students with the set of images to be analysed and processed.

\section{CONCLUSIONS}

The continuous growth and evolution of scientific and technological areas covered by the CIMET Master's Degree require innovative teaching methods by which the students acquire complete and up-to-date training in different subjects, both theoretic as well as practical. Furthermore, teaching based on traditional lectures can sometimes lead to a passive attitude on the part of students. Therefore, it is necessary to incorporate innovative methods to make the course more engaging for students while encouraging their participation in the teaching-learning process. One way to motivate student involvement in the teaching-learning process is by incorporating active methodologies.

In this work, we have presented a teaching methodology based on incorporating active-learning techniques into the course "Devices and Instrumentation" of the Erasmus Mundus CIMET Master's Degree. For this, students carry out several practical activities during the traditional lectures, using the software ImageJ. This software is free, its use requires no programming knowledge, and it is very rapid in the processing of digital images. These characteristics make it an ideal software for classroom use.

One of the innovative aspects of this teaching methodology is that students apply the concepts and methods studied in class using real devices. For this, students use their own digital cameras, webcams, or cell-phone cameras in class. These 
activities provide students a better understanding of the theoretical subject given in class and encourage the active participation of students, thereby completing the training received in the practical sessions of the laboratory.

\section{ACKNOWLEDGEMENTS}

The authors express their appreciation to the Universidad de Granada (Spain), for financing Proyecto de Innovación y Buenas Prácticas Docentes (código 12-207), and David Nesbitt for translating the text into English.

\section{REFERENCES}

[1] López, F., "Metodología participativa en la enseñanza universitaria,” Narcea, Madrid (2005).

[2] Nilson, L. B., "Teaching at its best," Jossey-Bass, San Francisco (2010).

[3] Barkley, E. F., Cross, K. P. and Major, C. H., "Técnicas de aprendizaje colaborativo: manual para el profesorado universitario," Ministerio de Educación y Ciencia, Madrid (2007).

[4] Ferreiro, R. and Calderón, M., "El ABC del aprendizaje cooperativo: trabajo en equipo para enseñar y aprender," Trillas, Sevilla (2006).

[5] Holst, G. C., "CCD Arrays, Cameras, and Displays," SPIE Optical Engineering Press, Bellingham, Washington (1996).

[6] Yadid-Pecht, O. and Etienne-Cummings, R. (Eds.), "CMOS Imagers: From Phototransduction to Image Processing," Kluwer Academic Publishers, Boston (2004).

[7] http://rsbweb.nih.gov/ij/. 